\title{
Isolamento social, sociabilidades e redes sociais de cuidados
}

\section{| ${ }^{1}$ Ivonete Alves de Lima Cavaliere, ${ }^{2}$ Suely Gomes Costa I}

Resumo: Este trabalho examina, em caráter exploratório, experiências de isolamento social vividas por indivíduos portadores de hanseníase, internados na ex-colônia Tavares de Macedo, em Itaboraí, onde foram mantidas da década de 1930 até os dias de hoje, para problematizar noções sobre segregação e discriminação social presentes nesse meio. Para tanto, examina sociabilidades e redes sociais de cuidados estabelecidas na vida em comum nessa "ex-colônia de leprosos", quase sempre como alternativas às condições oferecidas pelos sistemas públicos de proteção social. Faz isso com base em narrativas de alguns desses sujeitos, vistos em suas diferenças - nas interseçôes das relações por sexos, classes, raças/ etnias, gerações, e também por religiōes e graus de escolaridade. Recorre à história oral, modo de oferecer novas interpretações qualitativas de processos histórico-sociais evidenciados nessas sociabilidades e redes, nem sempre visíveis como formas singulares de proteção social da vida em comum.

> Palavras-chave: proteção social; isolamento social; rede social.
1 Psicóloga social, mestre em Ensino em Biociências e Saúde pela Fiocruz e doutoranda em Política Social da Escola de Serviço Social da Universidade Federal Fluminense (UFF). Endereço eletrônico: ivonetecavaliere@gmail.com

${ }^{2}$ Mestre e doutora em História, professora titular do Departamento de Serviço Social da UFF, pesquisadora do CNPq. Endereço eletrônico: suelygomescosta@gmail.com

Recebido em: 16/04/2010. Aprovado em: 25/02/2011. 


\section{Introdução}

No sentido de controlar e abolir a "lepra" no país, o isolamento compulsório representou a principal estratégia, e um conjunto de práticas com esse sentido irá perdurar entre início e meados do século XX. ${ }^{1}$ A partir de 1924, o governo decidiu pela internação compulsória de portadores de hanseníase: retira-os do convívio público, admitindo que isolar o doente resguardaria a sociedade sadia. Muitos dos "suspeitos de lepra", em geral, por denúncia de vizinhos, foram capturados em seus lares, tiveram suas casas queimadas e sofreram constrangimentos provocados pela internação.

No governo Vargas (1930-1945), sob a reclusão compulsória, os doentes eram tratados com medicamento fitoterápico. A partir de 1945, com o progresso da indústria químico-farmacêutica, dissemina-se o uso da sulfona e alguns pacientes terão alta médica. Em 1959, com a adoção desse medicamento pela "Campanha Nacional Contra a Lepra”, extingui-se a internação em "leprosários". Somente em 1962, entretanto, pela aprovação do Decreto no 968 , de 7 de maio, o isolamento é oficialmente extinto. Apesar disso, muitos doentes permaneceram internados e isolados. Esta política de internação compulsória só acabou de fato em 1986, quando foi recomendada a transformação de alguns "leprosários" em hospitais gerais. Na década de 1970, a Organização Mundial da Saúde recomendou o emprego da poliquimioterapia (PQT), e desde o início dos anos 1980, a doença vem sendo tratada em regime ambulatorial. Apesar de o tratamento dispensar a internação, algumas ex-colônias mantêm ainda moradores denominados "internos", nesses lugares até hoje. O Hospital Estadual Tavares de Macedo (HETM) é um deles.

Este artigo se apóia num conjunto de informes obtidos de entrevistas individuais semiestruturadas e áudio-gravadas. Ouvidas pessoas diversas, a seleção dos indivíduos para entrevistas teve caráter exploratório, adotando-se como critério inicial a condição de "interno" por eles declarada e a aceitação em participar da pesquisa. Todas as pessoas selecionadas ${ }^{2}$ têm em comum a permanência como moradoras nessa antiga colônia, embora internadas em diferentes momentos. Uma parte delas vivenciou o isolamento compulsório, enquanto outra conheceu o isolamento sem compulsoriedade. Algumas permaneceram residentes na excolônia, forma de acesso à assistência e ao tratamento sob o regime de asilo, numa experiência que ainda preserva marcas do isolamento. 
Do conjunto de experiências, selecionamos para este artigo algumas mulheres tomadas como pessoas que, em geral, produzem práticas de cuidados e proveem cotidianamente formas de ajuda recíproca apoiadas em diversos códigos sociais (COSTA, 2002), num campo de experiências configurado como de proteção social próxima ou primária (CASTEL, 2001). São mulheres moradoras do pavilhão feminino ou que residem em casas da colônia e que se mantêm de acordo com suas disponibilidades. Suas experiências oferecem um lugar de observação de situações compartilhadas e não compartilhadas coletivamente, em diferentes sentimentos a serem conhecidos. Indicações de que este meio, como outros, organiza sociabilidades e, delas, redes de ajuda, decorreram informes extraídos do conjunto mais amplo de entrevistas.

As entrevistas aqui apresentadas foram realizadas entre 15/06/09 e 14/09/09 e permitem repensar o quadro usual de análise das condiçôes de isolamento, considerando que favoreceram a distinção das desigualdades entre as pessoas. ${ }^{3}$ As condições narradas são entendidas também como representações do passado sobre o lugar dos "leprosos", reconstruídas psíquica e socialmente. Admite-se que este passado, em tempo algum, é somente o do indivíduo, mas o de um indivíduo inserido nas contingências familiares, sociais e nacionais (ROUSSO, 1996, p. 94), sempre plurais. Do mesmo modo, no momento atual, estudos sobre experiências de discriminação social e de isolamento, como as da questão judia e do Holocausto, têm favorecido revisões historiográficas e servido de referências para sucessivos desvendamentos de processos sociais ocultos de resistência às formas de convivência social.

Esta investigação, em conjunto, pretende superar a ideia da inexorável normatização da vida social nas políticas isolacionistas e contribuir com estudos sobre formas de resistência ao isolamento e mudanças de regras de convivência. Apóia-se esta assertiva em condutas que efetivam essas formas de resistência. As práticas de proteção social primária, largamente observadas nos estudos de gênero, têm evidenciado redes de cuidados que atuam sobre o ambiente social. No caso, indicam que, de muitas formas, incidem sobre o cotidiano dos internos em hospitais-colônia, seja atenuando, seja eliminando agruras da discriminação social e do isolamento. Por isso, como parte de um conjunto mais amplo de pesquisas, este trabalho se atém ao exame de alguns indícios sobre significados de experiências de isolamento social de mulheres - ex-portadoras de hanseníase da ex-colônia de 
Itaboraí, entre a década de 1930 e os dias de hoje. Essa abordagem pretende situar a relevância dos estudos sobre proteção social próxima (CASTEL, 2001) nos rumos das políticas sociais - e no caso dos da hanseníase, eles apenas se iniciam.

$\mathrm{Na}$ convivência oferecida pelo HETM, redes sociais efetivam apoio social e psicológico, mas quase nunca aparecem como parte inerente aos modos de vida aí engendrados. A história oral as revela, pois é um modo de "oferecer interpretações qualitativas de processos histórico-sociais” (LOZANO, 1996, p. 16) e de aproximação como formas singulares de proteção social presentes nessa vida em comum, mas nem sempre visíveis. Parte das pessoas selecionadas vivenciou o isolamento compulsório, enquanto outra, apenas o isolamento sem compulsoriedade, pois o Ministério da Saúde cancelará a prerrogativa da polícia sanitária de internar à força os/as doentes nos hospitais-colônias. Muitas dessas pessoas ficam na ex-colônia, como opção de assistência e tratamento, sob regime de asilo. Reconhecem-se desigualdades sociais entre as pessoas entrevistadas; e ainda, são muitos os silêncios quanto às formas de convivência entre aquelas mais e menos favorecidas.

Nessa etapa de pesquisa, evidencia-se que as experiências de isolamento são plurais: são diferenças de sexos, classes, raças/etnias, gerações, e também de religiōes e graus de escolaridade. Essas diferenças, todavia, têm sido diluídas em concepções totalizantes que tendem a classificar essas pessoas como um conjunto de doentes os mais excluídos dentre os excluídos. Além de diferentes, elas guardam entre si. Para Joutard (2000, p. 33), recorrer à história oral é “dar voz àqueles que normalmente não a têm: os esquecidos, os excluídos”, mas também é distingui-los uns dos outros.

A história oral, como indica François, "seria inovadora primeiramente por seus objetos, pois dá atenção especial aos 'dominados', aos silenciados e aos excluídos da história” e também, segundo o mesmo autor, por abordagens “[...] que dão preferência a uma 'história vista de baixo' [...]. No caso em estudo, ela se impóe, principalmente, porque lida com [...] as visões subjetivas e os percursos individuais, em uma perspectiva decididamente 'micro-histórica”" (FRANÇOIS, 1996, p. 4). Assim, desvenda a variedade das experiências observadas nesse grupo de doentes, quase sempre homogeneizado. Além disso, os depoimentos colhidos têm "condições de contribuir para a libertação do que está reprimido e para exprimir o inexprimível, pois, a história oral tem uma função propriamente 
política de purgação da memória [...]" (ibidem, p. 12). A memória construída sobre

a "lepra" se faz com representações de longa duração histórica: elas se atualizam como tantas outras e acompanham a discriminação e o isolamento de doentes; nem sempre exprime o inexprimível. Estas representações de muitas formas estarão também associadas às condições de pobreza e de desagregação familiar, de sofrimentos psíquicos decorrentes de rejeição, a situações de estresse e de baixa autoestima, tudo aquilo que contribuirá para deprimir o sistema imunológico do paciente, predispondo-o a agravar seu estado de doença (CLARO, 1995).

\section{Discriminação, segregação e convívio de hansenianos: revisões necessárias}

No passado, "quando se era dito e sabido 'leproso', a decisão estava entre matar-se ou segregar-se", mas depois, "os pacientes começaram a ter alta e a retornar ao convívio social", lembrando, por outro lado, que "a sociedade nunca deu alta ao ex-interno” (COIMBRA; MANCUSO; CARDOSO, 1996). Análises como essa da vida em "colônia" de hansenianos, com frequência, são subjacentes à noção de "instituição total” (GOFFMAN, 1974), criticada por Ignatieff (1987). Para esse autor, instituição total é o termo inventado por Goffman para todas as formas de instituição nas quais a autoridade busca regular totalmente a vida cotidiana de seus habitantes, por acreditar que as rotinas institucionais, quaisquer que sejam seus objetivos, oprimem. Em oposição a estas ideias, enfatiza Ignatieff (1987, p. 187): "O tema verdadeiro da história das instituições não é o que acontece dentro das paredes, mas a relação histórica entre o dentro e o fora”.

Goffman entendeu as colônias como "instituiçôes totais", admitindo o seu isolamento com o mundo exterior. Para ele,

toda instituição tem tendência de fechamento. [...] Seu fechamento ou caráter total é simbolizado pela barreira à relação social com o mundo externo e por proibições à saída que muitas vezes estão incluídas no esquema físico, por exemplo, portas fechadas, paredes altas, arame farpado, fossos, água, floresta ou pântanos (GOFFMAN, 1974, p. 16).

Em geral, registros de experiências como as de pacientes submetidos à política de isolamento compulsório são enunciados nessa perspectiva, como em Mancuso (1996, p. 35): a colônia, como um lugar organizado, seria aquele de espaço e horários disciplinados e de relações normatizadas, até mesmo (ou principalmente) as mais íntimas, como as de namoro. A desobediência às normas, assim, seria 
punida ou pela suspensão de algum direito (do de lazer, por exemplo) ou pela própria prisão seguida de castigos.

A colônia é assim significada através de uma representação de prisão, como também em análises de hospitais, reformatórios, de sanatórios e mesmo de mocambos, favelas, bairros periféricos etc. A ideia de colônia como uma instituição com regras rígidas de "dentro" e incomunicável com o mundo "de fora" representa bem o modelo de instituição total examinado por Ignatieff. Esse conceito tem, de muitos modos, similitudes com o de guetos, vistos como lugares de segregação, de privação total de liberdade, sem espaço para a vida social. De fato, a vida em colônia pode guardar semelhanças com a experiência dos guetos judeus, por exemplo, na medida em que também reforça a integração interior posta pelo isolamento em relação ao exterior, daí distinguir-se "nesse momento inaugural, os quatro elementos constitutivos do gueto, isto é, o estigma, a coerção, o confinamento espacial e o encapsulamento [encasement] institucional" (WACQUANT, 2008, p. 79), mas não só. A experiência do gueto judeu, hoje bastante documentada e estudada, revelou-se um espaço de muitas variações culturais e formas de vida social; não se trata, pois, de uma "instituição total”, porque também é local de resistências. Com múltiplas identidades, neles se organizaram manifestações de insubordinação exercidas de diversas formas, muitas imperceptíveis.

Há que se entender que os modos desiguais de segregação produzem diferentes formas de vida social, expressas em deslocamentos identitários e meios plurais de enfrentamento de condiçôes extremas de privação de liberdade. De acordo com Saraceno (1999), assim como não é possível falar de cultura hebraica sem levar em conta os campos de concentração, também não se pode pensar na reabilitação em psiquiatria sem levar em conta o hospital psiquiátrico. Do mesmo modo, não se pode falar do isolamento compulsório dos portadores de hanseníase, sem levar em conta as colônias e suas singularidades que incluem e ultrapassam a vida entre seus muros.

Nas colônias - como nos guetos judeus - o estigma, a coerção, o confinamento e o encapsulamento institucional podem também, por meio das redes sociais de cuidados, produzir e deslocar identidades e intercâmbios forjados no interior institucional em direção ao exterior. Este meio, com suas formas próprias de viver a vida social, nega-se como "instituição total”, considerando sociabilidades 
e redes sociais, sobretudo as que efetivam cuidados que aí se desenvolvem. Nesta

perspectiva e em caráter exploratório, examinamos experiências de vida social dessa unidade de saúde do Estado do Rio de Janeiro, admitindo-as como expressão de convivências e de interaçôes sociais que enfrentam privações de muitos impactos a serem avaliados sobre a política de "afrouxamento" do isolamento. Há situações específicas a observar: suspensa a segregação posta pelo isolamento compulsório para portadores de hanseníase, muitos ex-internos permanecem nas ex-colônias, com seus familiares e agregados. A manifesta "preferência” por este lugar, nesse contexto, nos tem sugerido um movimento de busca de revisão de conceitos-chave sobre o isolamento extraído de experiências das pessoas que detêm a condição de “internas"4 no hospital-colônia.

As fontes orais sobre este hospital mostram que muitos ex-internos, homens e mulheres, permanecem nesta ex-colônia como opção de assistência e tratamento, aparentemente reproduzindo o regime de asilos. Tais escolhas, ainda que com marcas de sofrimento, parecem ter favorecido a ampliação de trânsitos entre dois mundos vistos como separados: o de "dentro" e o de "fora". Manter-se "interno" pode ser uma questão não apenas de segregação ou de exclusão, mas sim de vivências/ experimentos que dão continuidade à restauração de identidades e de conhecidas formas de vida social. O sentimento de pertença à categoria de "interno" parece advir de condições de seguridade social que englobam benefícios, facilidades e, para alguns, remuneração (CAVALIERE, 2009), mas também domínio de muitas possibilidades de vida social entre iguais e diferentes. A experiência de vida dentro da colônia após o isolamento, vista como parte da comunidade e de seu entorno, pode representar a construção da vida social na sociedade "extra-hospitalar" como mais um desafio a enfrentar com novos percalços.

Experiências dessa unidade mostram processos e relações sociais que explicitam formas de convivência entre mundos só aparentemente apartados: o de "dentro" e de "fora", em geral de notável invisibilidade. Elas incidem permanentemente na superação de condições de isolamento, já não mais impostas por lei. Essas formas são aqui traduzidas como significativas também de proteção social da vida em comum. Com base em muitos indícios colhidos nas entrevistas realizadas, verifica-se que, mesmo sob o isolamento, as sociabilidades estariam sempre acionando a formação de redes sociais, com relevância, como indicado, para as que efetivam práticas sociais de cuidados. 
Elas atuam sobre condições usuais de isolamento. São práticas de longa duração histórica e, por séculos, os "leprosos" as têm experimentado, como indicam muitos registros, inclusive literários, como os conhecidos Tristão e Isolda, de autor anônimo, e $O$ Visconde Partido ao Meio, de Ítalo Calvino.

A dimensão assumida pelos cuidados constitui matéria de interesse dos estudos sobre proteção social, em especial sobre assistência social. Nas experiências examinadas, ainda que de caráter preliminar, crescem de significados os alcances das práticas de cuidados, sobretudo quando a vida social sob não-isolamento guarda continuidades com aquela vivida sob isolamento. O conhecimento destas práticas e das redes sociais que as organizam muda a percepção da dinâmica do isolamento, sobretudo nas situações de apoio social e psicológico para o enfrentamento de privaçōes e sofrimentos, quase sempre em alternativas às condições postas pelos sistemas públicos de proteção social e até mesmo como resultados delas.

Os estudos de sociabilidades são relevantes para isso. Destaque-se que eles conheceram diferentes momentos. A matéria aparece, inicialmente, nas preocupações de Simmel (1983), que enuncia a sociabilidade como "a forma lúdica da sociação". Diferentes pensadores a veem como um fenômeno social e como uma forma de interação na qual os participantes autonomizam suas atuações, sem qualquer demonstração de interesse objetivo nos assuntos tratados, noção esta que o autor ilustra com o exemplo de conversa em festas. Este conceito irá se adensar.

Estudos de formas de sociabilidade formam a base empírica construída ao longo do desenvolvimento das ciências sociais, em especial da sociologia, diante das questóes postas pela dualidade entre a sociedade industrial e o mundo rural, em análises ora de oposição, ora de complementaridade. Com Weber (1979), assume o conceito de millieu - ou meio - econômico. Em Thompson (1998), vincula-se à formulação do conceito de economia moral. Scott (2002) a associa ao conceito de resistência cotidiana e Bourdieu (1963), ao de consciência temporal. Esses e tantos mais autores com tais contribuiçôes levaram à apreensão das muitas variações da vida social. Mais que uma categoria de interação social, a sociabilidade será entendida como um ponto de partida para se examinar a dinâmica da experiência vivida e de modos sociais de organização de um dado grupo social num dado tempo e espaço, bem como de produção de códigos sociais e padrões culturais em seus aspectos ambíguos e contraditórios. 
Outro conceito útil a esta análise é o de redes sociais; presentes em muitas práticas sociais, em geral as redes são tão "naturais" que permanecem invisíveis. Merece destaque nos estudos de gênero a presença de redes de proteção social primária (família e grupos de convívio) organizadas por mulheres em suas práticas costumeiras de cuidados (COSTA, 1995, 2002, 2009; FREIRE, 2006; PINTO, 2007). Sua forte presença está na história das mulheres de todos os tempos e lugares, como indicam diferentes autores/as, e também confirmada naquela recolhida de entrevistas realizadas na ex-colônia e que servem a este estudo. Atender, socorrer, amparar e também segregar fazem parte da vida em comum dos moradores na ex-colônia, mesmo quando de níveis sociais distintos. Sublinhe-se que, em todos estes casos, as mulheres, após o tratamento e obtida alta médica por cura, permaneceram e permanecem morando nas dependências da antiga colônia.

\section{Relações de "dentro" e de "fora"}

As interações do mundo "dentro" e "fora" da ex-colônia em questão oferecem algumas pistas para o reexame das condições de isolamento. A ex-colônia ocupa uma área de um milhão de metros quadrados e está localizada no município de Itaboraí, por longo tempo de significativa atividade agrícola e hoje integrante da região metropolitana do Rio de Janeiro. A administração do HETM estima que nesse meio haja cerca de 7.000 habitantes, entre ex-pacientes, residentes na área hospitalar e na área comunitária, com seus agregados e familiares. O hospital possui cinco enfermarias nas quais residem os idosos com dificuldade de locomoção devido às sequelas da hanseníase ou mesmo à idade avançada. Há, ainda, 515 pacientes “internos” com seus familiares, destes, 437 residem em casas, 34 distribuem-se em nove pavilhões, além de 44 em enfermarias.

As relações construídas no interior da ex-colônia entre famílias semelhantes, num primeiro exame, parecem silenciar sobre o amparo do meio externo. A discriminação dos "leprosos" na longa duração histórica os confina, por séculos, em espaços separados. De algum modo, essa percepção se impõe. Aqui cabe trazer as análises de Elias (2000) sobre "os estabelecidos" e os outsiders como um modo de exame dessa convivência. De maneira semelhante àquela estudada por Elias, no município de Itaboraí seus habitantes também são considerados os "estabelecidos" e os "leprosos", os outsiders. 
Nessa oposição, deterão poder os grupos que, com base na antiguidade da experiência do lugar, teriam estabelecido confrontos com os "estigmatizados por atributos associados" não "a violência e desintegração" (ELIAS, 2000, p. 7), mas ao estigma da "lepra”. "Os estabelecidos", no caso em estudo, se autopercebem como "sadios" e pertencentes à "boa sociedade"; exercem o poder disciplinador do espaço, através de regras constituídas pela tradição e pela autoridade com relação aos outsiders, aqueles que estão fora da "boa sociedade". Nesse sentido, registros disponíveis sobre o passado recente indicam que "os estabelecidos", por rejeição aos doentes, manifestaram-se contra a instalação da Colônia Tavares de Macedo, em protestos conduzidos pelas elites locais. E tudo indica que isto se fez em razão da discriminação que a região por inteiro passaria a sofrer, como uma forma de defesa à vida social "normal". A memória sobre a vida social da colônia não é guardada apenas como a "preservação da informação, mas também como sinal de luta e como processo em andamento. [...] não apenas como um lugar onde você 'recorda' a história, mas a memória como história” (PORTELLI, 2000, p. 69).

Nas décadas de 70 e 80, a rejeição dos "de fora" se manifestou em defesa do "lugar". Sobre o município e sobre o conjunto de moradores da colônia, caía indistintamente uma mesma atmosfera pesada posta pela presença da "lepra" nesse território. Também fica perceptível, aí como resultado das exploraçôes iniciais, que as tensōes nesses espaços de "dentro" e de "fora" da colônia irão se modificar e se atenuar. No caso estudado por Elias: "o curso efetivo dos acontecimentos assume seu significado e seu sentido, para os homens envolvidos nele, através da elevação ou diminuição em esquema prévio de valorização" (p. 209).

Essa valorização leva a comparar diferenças em relação ao sistema de exclusão dos loucos, sujeitos incapazes para os atos de vida civil. Ao contrário, os hansenianos exercem o direito de voto, por exemplo. Isso significará que, em conjunto, contraditoriamente à segregação, compõem um eleitorado a ser sempre conquistado. $\mathrm{O}$ uso dessa prerrogativa política os valoriza, enseja e renova o clima de esperança de melhorias do lugar também sob contingências científicas que avançam, atenuando a percepção da contagiosidade da "lepra" e mesmo admitindo sua cura, reduzindo, com o passar do tempo, o medo dos riscos de contaminação da coletividade maior. De fato, políticos circulam na colônia e entram em contato com seus moradores; dirigem-se a eles com suas 
propagandas e promessas, patrocinam formas associativas, como clubes, times de

futebol e torneios, além de festividades que se tornaram famosas na região e que fazem interagir pessoas de "dentro" e de "fora" da colônia (LIMA, 2005). Há por distinguir/examinar essas circunstâncias de diferentes tempos.

Os depoimentos de hoje sobre a vida social na colônia confirmam isso nas "memórias" "daquelas" festas marcadas por "saudosismos". Mesmo que, a partir da década de 80 e das décadas seguintes, o período do não isolamento se instale, há por destacar que a atuação de interventores designados para desarticular o autoritarismo e diversos mecanismos de controle mantenha, por razões diversas, práticas disciplinares, tais como "toque de recolher" e vigilância feita por guardas internos. Aos poucos, sem data demarcada, a intervenção do governo estadual as desarticula e as regras da "colônia" mudam, favorecendo a entrada de muitas pessoas, inclusive de "invasores" e pessoas indesejadas, como assinala Tereza (71 anos), moradora da colônia desde 1963: “Tenho saudades dos bailes de antigamente, agora só tem baderneiros, que fazem barulho, música alta e violência. Às vezes, ouço tiroteio; fico com medo".

$\mathrm{Na}$ opiniāo de moradores entrevistados, esse millieu, ultrapassado o período do isolamento compulsório, não evidenciaria qualquer "divisor de águas" entre o tempo sob isolamento e depois dele. Abertos os portóes da colônia, poucas pessoas saíram e muitas entraram. O caso de Tereza, 71 anos, é exemplar: "A porta estava aberta, eu podia sair, mas não tinha para onde ir". Esse "não ter para onde ir" parece significar uma avaliação do modo de vida possível de construir sob certas circunstâncias, sem necessariamente traduzir uma "adaptação" a ela. Prossegue: "Vim para cá com 21 anos. O médico me disse que eu ficaria boa em seis meses, mas já se passaram 50 anos e ainda não estou curada". Ela, porém, dá sinais de que não reunia condições físicas nem psicológicas e muito menos financeiras para enfrentar o mundo "lá fora", mesmo porque ela podia transitar entre estes mundos, só aparentemente apartados.

Os dispositivos legais e/ou regulamentares de administração da "entrada" e da "saída" hoje estão abandonados: com uma simples identificação, ingressase na ex-colônia, como em qualquer conjunto institucional ou residencial. As mudanças do isolamento e suas repercussōes sobre a vida social no interior da colônia ocorreram ao longo dos anos. Vantagens evidentes foram conquistadas, como indica Mariela, 57 anos: "Se não fosse pela hanseníase, eu não estaria tão 
bem de vida quanto estou hoje, por causa dela consegui um emprego fixo no Estado, moro de graça e como 'na geral' [o refeitório]".

Esse millieu é um espaço interceptado por condutas afetivas que organizam práticas de cuidados, em grande parte, como indicado, protagonizadas por mulheres. A experiência de pertencerem a um grupo considerado "outsider" não as exime de elos identitários. Direta ou indiretamente, essas vidas compõem um universo de afetos forjados, em grande parte nos estreitos vínculos de amizade que as mulheres casadas e com filhos mantêm entre famílias, por relações de compadrio. Nessas relações, não houve, no período desta pesquisa, registro de "aversão" entre membros das famílias que residem fora ou dentro da colônia. Os informes que nos chegam são de que as pessoas se reúnem sempre nos domicílios: apoiam-se em atividades como conduzir crianças para escola, preparar festas de aniversários e o churrasco do fim de semana. Lena, 31 anos, professora de uma das quatro escolas do entorno da colônia, sinaliza: "A gente se reúne para comemorações, ora na minha casa, ora na casa de minha comadre. Deixo meu filho na casa dela para ir trabalhar e fico tranquila".

Por outro lado, embora a colônia ofereça um serviço de interesse público, como a Biblioteca "Mestre Aleijadinho", este é um espaço pouco frequentado, apesar de seu bom acervo. Talvez isso ocorra por precauções quanto à persistência do medo de contaminação. As igrejas católicas e evangélicas sediadas na ex-colônia, entretanto, são bem concorridas, com presença de pessoas de fora da colônia. Jonas, 74 anos, antigo morador, registra, todavia, ter observado, numa missa, uma pessoa de fora se comportando com certa "precaução". Consta que até o final da década de 50, por todos os males que se possa imaginar, era inaceitável que alguém da cidade de Itaboraí se introduzisse nessa "cidade de leprosos". Contudo, no final dos anos 60, festejos, times, torcidas, concursos de rainhas do carnaval, de miss etc. promoveriam, ao longo dos anos, não a plena interação da colônia com a população do município, mas mudanças comportamentais que evidenciam sensível aceitação social.

A inserção em acontecimentos sociais locais, idas e vindas ao comércio, ao médico, aos bancos e praças públicas são parte de processos que acabaram fortalecendo as relações sociais construídas no dia a dia, de "dentro" e de "fora". Os cuidados que idosas, por exemplo, recebem através de situações e pessoas diversas, podem, aqui e ali, sugerir isolamento por viverem em pavilhão do 
hospital. No entanto, pessoas com liberdade cerceada devido a sequelas da doença e/ou a problemas peculiares à idade avançada, por não poderem transitar, se vivessem fora da colônia teriam dificuldades de se relacionar com outras pessoas.

Eugenia, 94 anos, depois de ter vivido por 37 anos numa casa no interior da colônia, beneficiou-se, nos últimos três anos, em morar no pavilhão, pois de outra maneira não daria conta das tarefas domésticas, nem das de administração de sua própria medicação. E essa condição a coloca em contato com o mundo exterior. Ela se refere à "boa" assistência recebida: "Um dia estou melhor, no outro estou pior, mas conto com as colegas de pavilhão e com uma boa assistência da enfermagem. A ambulância vem me buscar para me levar ao posto de saúde". Com bom humor, entretanto, relembra: "Fui internada no hospital [leprosário] de São Cristóvão, morei lá quatro anos. Foi onde conheci um solteirão e casei com ele. Lá fizeram uma festa muito bonita e nós caímos na dança. Foi muito bom. Viemos para essa colônia aqui porque lá não podia ficar casado”. Esta exportadora de hanseníase traz à baila memórias de cuidados que algumas amigas lhe asseguram, sublinha a boa lembrança de seu relacionamento conjugal neste espaço, sempre pensado, como de confinamento.

Ainda que a memória de pessoa adulta reflita a existência, não como uma paisagem vista de uma estrada, mas como uma estrada com algumas sinalizações ocasionais, segundo alguns autores (SCHACHTEL apud MANCUSO, 1996), a entrevistada registra referências que representam acontecimentos felizes, como seu casamento e a morada na colônia, considerando ser essa a possibilidade de conviver com seu marido. Os eventos ligados aos sofrimentos postos pela hanseníase, nesse caso, não estão sendo mais lembrados com a intensidade com que foram vivenciados no passado. A depoente, ao falar do seu estado atual de saúde e cuidados recebidos, recorda seu casamento e sua morada. Nesse caso, ao expor sua experiência, ela deixa de falar do estigma, sempre uma dolorosa marca entre os hansenianos, e se mantém focada nos cuidados que recebeu e recebe de dentro e fora do hospital.

\section{Cuidados, sociabilidades e redes}

Cuidados criam vínculos identitários, mas também funcionam como moedas de troca (MAUSS, 1974), como destacado em estudo recente: "no caso das redes, a obrigação de retribuir favores prestados também acontece, trazendo resultados 
para os agentes nem sempre satisfatórios" (PINTO, 2007, p. 21). Cuidar por algum tempo de alguém pode significar a expectativa de receber em troca, algum dia, cuidados também, como conta Sara, 43 anos: "Encontrei o homem muito doente, suas feridas minavam, fazia seus curativos e lavava a roupa de cama todo dia. Eu pensava: se 'lepra' pega, já peguei. Cuidei dele e, depois quando minha doença apareceu, ele cuidou de mim”.

Soninha, 70 anos, pelos cuidados que ela oferece ao filho, também parece esperar dele compensações afetivas. No entanto, em algumas ocasiōes, deixa escapar uma lamúria: "eu preciso ajudar meu filho porque ele ganha pouco e vive apertado”. Com isto, proclama a dependência financeira do filho em relação a ela. São também inquietações de uma mãe que representa, como usual, a maternidade em sua função privada e social, remetendo à acepção de feministas dos anos 20 do século XX, como "merecedoras de remuneração" por serviços prescritos pela ideologia do "maternalismo" (BADINTER, 1985). Ela se sente merecedora da “atenção próxima” dos filhos, pois de rede social alargada está bem servida pela presença constante, em sua casa, de amigas e vizinhas, bem como de assistentes sociais. A preocupação dela, ao zelar pela proteção do filho, parece expressar uma dada expectativa de reciprocidade. A dinâmica dos cuidados mostra que há laços familiares como esses que não agregam. Há outros, porém que os recompõem. Esse é caso de Gorete, 40 anos. Narra ela: "Quando minha mãe ficou maluca, meu pai a abandonou no hospital de Jurujuba. Com o dinheiro de minha mãe ele comprava remédio e alimento para outra mulher. Fiquei revoltada. Então, encontrei uma tia que cuidou de minha mãe e me ajudou muito”.

Tratar deste ambiente e da recolha de informes familiares sobre cuidados exige cautelas investigativas. Na vida familiar, há que se distinguir uma vasta rede de relações narradas por diferentes óticas, construídas por diferentes memórias, como na experiência da "memória dividida"s de que fala Contini (apud PORTELLI, 1996). É um desafio estabelecer o protagonismo de cada membro da família diante de uma mesma história; para isto, cabe sempre localizar cada um dos familiares na experiência de vida familiar e/ou diante de um dado evento. De todo modo, as muitas versões de uma mesma história ou de um mesmo evento podem traduzir aquilo que teria se tornado a versão "oficial” da experiência, quando as demais versões podem oferecer subsídios para o exame de representações que circulam no mesmo ambiente, e que fornecem sobre ele distintas versões. Redes 
sociais de cuidados oferecem muitas possibilidades analíticas, ainda mais quando podem envolver afeto com relação remunerada.

Se para Mauss (1974) toda ajuda tem uma retribuição, e se onde tem rede tem favor, evidencia-se que as relações de afeto não estão isentas de obrigações e nem sempre são totalmente livres do financeiro; por outro lado, também podem não ser pautadas somente pelo dinheiro. Há uma mistura das dimensões de favor, de troca e de elementos afetivos. Neste sentido, o trabalho de cuidador gera valor. $\mathrm{Na}$ publicação The purchase of intimacy, Zelizer (2005) apresenta o caso da cuidadora Bárbara Johnson (34 anos), de origem pobre, que se tornou esposa e reconhecida herdeira de Johnson (76 anos). Zelizer abre uma série de debates sobre familiares e cuidadores, ${ }^{6}$ e neste caso mostra que está quebrado o paradigma de família sempre boa e os de fora sempre interessados na fortuna do doente. Contudo, talvez por precaução, nos EUA, como noutros países do mundo, os membros da família continuam sendo os principais cuidadores dos familiares.

Alguns estudos mais recentes sobre cuidados trazem novas perspectivas para o exame de sociabilidades e redes. Com eles, identificam-se novas formas de sociabilidades (TEIXEIRA, 2008; CAVEDON, 2007; DOIN, 2007; COSTA, 2007; MORIGI; PAVAN, 2004; TRUZZI, 2008). Este trabalho destaca indícios úteis para o exame de sociabilidades de indivíduos unidos por laços de parentesco ou afins, de amizade com pessoas conhecidas que, nos modos de vida no interior de uma ex-colônia, ao contarem com apoio mútuo, formam relações sociais de muitos elos e significados, imersas em referências culturais diversas. Lembra DaMatta que, na América do Norte, a existência social é praticamente impossível sem a conta bancária, cartão de crédito e o social security number, enquanto que no Brasil, há milhões que vivem sem nada disso. A diferença é que lá as pessoas podem dispensar muitos laços sociais instrumentais de cuidados. Já entre nós, "ninguém existe de modo social pleno sem ter uma família e uma rede de laços pessoais imperativos e instrumentais" (DAMATTA, 1987, p. 101).

$\mathrm{O}$ conceito de rede, inaugurado pela sociologia e pela antropologia social, terá primeiro um uso metafórico deixando de associar relaçóes e o comportamento dos indivíduos que as constituem. Em As estruturas elementares do parentesco, Claude Lévi-Strauss localiza a noção de rede quando admite que uma relação "[...] não pode ser isolada arbitrariamente de todas as outras, e também não é possível que o indivíduo se mantenha aquém ou além do mundo das relações [...]. O meio 
é inseparável das coisas que nele habitam" (1982, p. 523). Também Bourdieu (1980), ao examinar estratégias de investimento nas relações passíveis de serem utilizadas como fonte de benefícios em seus estudos sobre capital social, ${ }^{7}$ indica que esse depende da amplitude da rede de ligações entre indivíduos quanto a dispor e a disponibilizar certa quantidade de capital (econômico, cultural ou simbólico) de cada um. Elias (1994, p. 35), por sua vez, destaca não o caráter indissociável da noção de rede, mas sua reciprocidade. Para ele "a rede só é compreensível em termos da maneira como eles [os fios] se ligam, de sua relação recíproca”. Para Silvia Portugal (2007), o termo designa grande variedade de objetos e fenômenos:

[...] a construção de um sentido analítico para o conceito de rede social desenvolveuse em torno de duas correntes: uma, que emerge da Antropologia Social britânica do pós II Guerra Mundial, e se preocupa fundamentalmente com uma análise situacional de grupos restritos; outra, sobretudo americana, que se prende com o desenvolvimento da análise qualitativa, no quadro de uma abordagem estrutural (PORTUGAL, 2007, p. 3-4).

Com Elizabeth Bott, os estudos sobre famílias passam a incorporar a noção de rede ao levarem em conta seu contexto social. ${ }^{8}$ Essa noção é referida a pessoas conectadas em diferentes pontos de um sistema social, como canalículos; difere da ideia usual de grupo vista como reunião de indivíduos organizados em torno de uma causa comum, partilhando uma cultura específica e formada pelo paradigma da totalidade. ${ }^{9}$ Rede seria, assim, um conjunto de relações; nele, um indivíduo pode ocupar várias posiçôes: "A rede é definida como todas ou algumas unidades sociais (indivíduos ou grupos) com os quais um indivíduo particular ou um grupo está em contato" (BOTT, 1976, p. 299). A autora destaca ainda a relação conjugal, concluindo que quanto menor for a conexão da rede, menor será o grau de segregação entre os papéis do casal, pois contando menos com uma rede, tende-se a compartilhar decisóes e tarefas domésticas. Seu argumento é o de que a dinâmica da estrutura familiar depende não apenas do comportamento de seus membros, mas também das relações que estes estabelecem com outros. A estrutura da rede de parentes, amigos, vizinhos e colegas tem influência direta na definição das relações familiares.

Para o caso em estudo, vale destacar toda uma genealogia de como as pessoas cuidam umas das outras a partir de várias redes de cuidados, que fazem as pessoas interagir e formam um conjunto de relações interpessoais concretas que vinculam uns indivíduos aos outros (BARNES, 1987). Interessa-nos, aqui, 
compreender os vínculos estabelecidos no cotidiano dessas pessoas em relação a seus vizinhos, familiares e amigos. Nessas relaçóes, proximidade e reciprocidade ajudam a compreender como se materializam condições de vida peculiares a essa comunidade formada por ex-portadores de hanseníase moradores da ex-colônia, mesmo isentos da obrigatoriedade de lá habitarem. Chegados à colônia, alguns contraíram núpcias, ampliaram a parentela, constituíram seus descendentes e agregados, esses com que forjaram laços, formando assim uma comunidade em ampliação, diríamos, de pacientes e "simpatizantes".

As relações nesse contexto de vizinhança, muitas vezes problemáticas, envolvem, além de alianças, conflitos surgidos por meio de fofocas (FONSECA, 2004). Gorete, entrevistada, indica que seu pai, apesar de deformado pelas sequelas da hanseníase, arranjou namorada. Percebe-se que uma doença não impede a aproximação de pessoas. No caso, se cria repulsa, também engendra aproximações e rede social. As sequelas da hanseníase compõem materialmente o estigma da "lepra", como dirá um internado: "É como se pegasse um ferro quente e te marcasse para sempre" (apud COIMBRA et al., 1996, p. 2). A "lepra" é representada como doença que desfigura, e como tal, ela cria sentimentos de repulsa, afasta pessoas e à primeira vista segrega todos que a portam, homens ou mulheres, numa experiência que parece se confirmar a cada tempo. Essa seria uma dificuldade posta ao processo de formação de identidades entre pessoas "sadias" e "doentes". Além disso, a deformidade do corpo, em especial, penaliza fortemente as mulheres; elas conhecem bem as agruras de não serem belas, ainda mais se desfiguradas por razões quaisquer. $\mathrm{O}$ olhar do outro é o que determina a classificação de feiúra ou da desfiguração, e com ela, os termos de convivência social: "por seu olhar impiedoso que revela a nossa feiúra ou a nossa vergonha, ainda podemos nos iludir com a possibilidade de que esses outros não nos vejam como somos. No inferno sartriano [...] o inferno são os Outros" (ECO, 2007, p. 89).

Firmina, 43 anos, é filha de uma mulher desfigurada pela "lepra" que, diante do adultério do marido, cometeu suicídio. A desfiguração de corpos marca conhecidas dificuldades de relacionamento com os outros e de formação de redes. O trágico relato de Firmina sobre sua mãe, morta depois de atear fogo no próprio corpo tantos anos atrás, nos encoraja a avaliar a extensão das dificuldades femininas de viver e conviver com a desfiguração trazida pela doença e as dificuldades aí colocadas de contato social. Durante a entrevista, Firmina, ao 
destacar detalhes dos curativos que fizera no corpo extensamente queimado de sua mãe, descreve o cumprimento de sua função/obrigação de cuidadora, como filha, mas também um ato de amor. Logo depois de um longo intervalo de silêncio, registra informes, aparentemente negligenciáveis, sobre a ausência do cuidado médico neste episódio. Sua memória parece preservar um ressentimento (BRESCIANI; NAXARA, 2004), associado a uma possível rejeição por nojo experimentado pelo profissional no trato deste corpo ferido. Conta, então: "Ela ficou jogada, sem tratamento, nem médico queria botar a mão” (muxoxo).

Com este gesto, faz expressar sua censura à falta do necessário cuidado médico a esse corpo desfigurado, nessa história vinda do passado. Mas de imediato, neste seu tempo presente, desloca-se para outras experiências de destrato por ela sofrido no mundo de "dentro" e no de "fora". Logo após a narrativa sobre a mãe, registra: "Quando meu companheiro morreu, para esquecê-lo, fui morar fora da Colônia, mas não deu certo. Voltei e, morando de favor em casa de uma 'amiga', fui humilhada. Ninguém me ajudou". Na colônia, narra, internos/as continuam perseguindo-a, por onde passa, com a pecha de "louca como a mãe".

Sem marcas da hanseníase, este olhar do outro não deixa de propagar na colônia, entre internos/as, e aos quatro ventos, um estado de loucura visto como transmitido de mãe para filha, razão para mais uma discriminação entre assemelhados na doença, agora acrescida de mais um atributo que a segrega: "louca como a mãe". A medicação para combater as dores dessa doença provoca reações físicas e desequilíbrio emocional, o que a caracteriza como "doente dos nervos" ou louca. O olhar dos outros, hoje, classifica como loucas sua mãe e ela. Como "mulher nervosa", vive a situação que regularmente discrimina e penaliza as mulheres irritadiças, predestinadas a serem calmas, joviais, ternas...

Momentos muito difíceis cercam sua história pessoal, marcada por resistências e transgressōes oferecidas às regras disciplinares do HETM. Ela nasceu na Colônia. De acordo com normas então vigentes, foi separada da mãe e levada para o orfanato, o Educandário de Vista Alegre, do qual fugiu. Firmina relembra: "Eu fugi do educandário com 13 anos para ficar com minha mãe. Ela me trancou dentro do guarda-roupa, para me esconder porque, nos anos 1970, não podia ficar filho de doente na Colônia”. Nesse ato simbólico, a mãe a protege rompendo regras de isolamento. Narra que, ao sair da companhia da mãe, perambulou pelas ruas e se instalou numa casa próxima da colônia, modo de estar furtivamente 
com a mãe, na condição de doméstica sem pagamento, em troca de alimentação e moradia. A patroa dizia que estava lhe fazendo um favor. Ela sabia que estava sendo explorada e, mesmo sob maus-tratos, diz-se agradecida pela ajuda. Do lado de fora da colônia e, por muito tempo, ficou nos seus arredores, sempre como modo de assegurar a aproximação de sua mãe, até que conseguiu voltar a morar lá dentro, restabelecendo vínculos familiares. Essas pessoas também traçam redes de ajuda, mesmo sob intensos constrangimentos, como nesse caso, sentidos como uma graça... Firmina diz desconhecer qualquer rede primária de cuidados. Por outro lado, destaca o bom atendimento do sistema público de seguridade social: "Sofro reação da talidomida, mas me trato e sou bem atendida no ambulatório". O trabalho das instituições também forja redes de cuidados.

As histórias acima narradas mostram algumas relações entre "atores sociais", algo que remete a Bruno Latour (2005). A teoria ator-rede concebe pessoas conectadas num sistema de várias redes engendradas em diversos tipos de coisas que são configuradas nesse processo (território, família, afeto, política pública). Para o autor, "esta teoria tem a seguinte implicação: a sociedade não é o ponto de partida - como em Durkheim (1912)-mas o ponto de chegada de relações. E já que parentes são antes de mais nada redes de relações (STRATHERN, 1995), faz sentido falar de atores-redes como os sujeitos dessa ontologia relacional" (LATOUR apud ALMEIDA, 2009). Nada mais útil para começar a repensar o isolamento social, as sociabilidades e as redes sociais de cuidados no caso da hanseníase.

\section{Conclusão}

Como indicado, este trabalho exploratório busca rever, no campo da atenção à hanseníase, alguns paradigmas que concebem a "colônia" como instituição total, mas não reduz esta questão a uma problemática exclusiva da saúde. Numa aproximação com campos teóricos destinados a decodificar aproximadamente as experiências de segregação e discriminação social, pretende destacar a construção da vida em comum em experiências vistas em alguns indícios (GINZBURG, 1991)-eles portam algumas surpresas. Neste exercício, tomamos a experiência da hanseníase como também capaz de produzir novas possibilidades de vida e de relaçôes sociais, práticas de relaçôes interpessoais e muitas experiências de proteção social. Conhecer as histórias de vida, as circunstâncias e o significado do confinamento para analisar atitudes e comportamentos, posturas dentro 
do mundo, em geral, tido como fechado, e/ou limitar-se ao conhecimento científico da doença, não basta.

Resultados desta abordagem apenas exploratória sugeriram matérias a serem aprofundadas em etapas posteriores de pesquisa. Hoje, a vida social da colônia parece se confundir com a do município; há nexos entre as esferas pública e privada a serem mais bem examinados e isso não se fez por acaso. A institucionalização da função pública ganhou ampliaçōes e, certamente, também redefiniu significados e labores de redes sociais da esfera privada. "Dona Magda", por exemplo, senhora que, no passado, prestava assistência pessoal aos internos intercedendo junto a médico, previdência social etc., tem hoje sua função desenvolvida pela Igreja católica, com cestas básicas e manutenção de um bazar; por espíritas que trazem caravanas de doadores; por evangélicos que desenvolvem atividades religiosas e doações. Além disso, há o Serviço Social e seu trabalho é realizado em enfermarias, pavilhões e comunidade a partir do idoso e seus familiares, com acolhimento e orientação sobre os direitos sociais, ações de educação em saúde, em ambulatório, cobertura de demanda espontânea sobre viabilização de órteses e próteses pelo SUS, bem como de previdência social, LOAS (Lei Orgânica da Assistência Social) e PBC (Proteção Básica Continuada). As redes privadas prosseguem, continuam presentes e oferecem um campo de experiências a ser desvendado.

As aproximações aqui expostas, ainda que exploratórias, indicam que, em cada época, sociabilidades e redes de cuidados formataram práticas de ajuda social em intrincadas relaçôes sociais que tanto ressignificaram a doença como a dinâmica da vida em comum. $\mathrm{O}$ experimentado como passado se moveu diante das expectativas de vida futura, colocadas pela cura do mal de Hansen. Experiência e expectativa "dirigem as ações concretas no movimento social e político” (KOSELLECK, 2006, p. 308). O sofrimento decorrente do isolamento social, aliado à necessidade de cuidados, mobilizaria ex-portadores/as de hanseníase em direção à superação de uma dada experiência de segregação social. Formas de enfrentamento deste sofrimento variam segundo experiências diversas no tempo e favorecem a expectativa de invenção do presente. Evidenciou-se nas experiências estudadas que os sujeitos históricos "agem" e não apenas "reagem" (CHALHOUB, 1996), lembrando ainda Certeau (1994): a vida social se fez e se faz com criação e utilização de táticas de sobrevivência. Na dinâmica das relações humanas, indica ele (p. 47), "muitas práticas cotidianas (falar, ler, circular, fazer 
compras ou preparar as refeições, etc.) são do tipo tática [...] vitórias do 'fraco'

sobre o mais 'forte' (os poderosos, a doença, a violência das coisas ou de uma ordem etc)". A colônia é uma cidade dentro de outra em uma tensa convivência; ela lutou e luta, mas não se organizou para atacar a cidade de Itaboraí ou dela se defender, mas usou e usa as práticas comuns de convivência humana.

Hoje, como parte da região metropolitana, esse município tem imensos contingentes de pobreza, o que talvez tenha facilitado mudanças nas formas de segregação da colônia. Também na vida social da colônia houve e há estratégias que "postulam um lugar capaz de ser circunscrito como um próprio e, portanto, capaz de servir de base a uma gestão de suas relações com uma exterioridade distinta" (idem, p. 46), moveu conceitos anteriores sobre a vida nessas colônias. Formas de organização coletiva dependem de redes sociais. Isto acontecerá no futuro das vidas passadas em colônia quando emergirá o MORHAN (Movimento de Reintegração das Pessoas Atingidas pela Hanseníase), experiência que confirma a efetividade das lutas travadas contra a segregação e a discriminação dos "leprosos". Sem sociabilidades experimentadas e sem redes sociais construídas, nada disto seria possível.

\section{Referências}

ALMEIDA, M. Ementa Disciplina Organização Social e Parentesco - HS 181. Programa de Pós-Graduação em Antropologia Social, Mestrado. Campinas: UNICAMP, 2009.

ANÔNIMO. Tristão e Isolda. Rio de Janeiro: Livraria Francisco Alves, 1982.

BADINTER, E. Um amor conquistado: o mito do amor materno. Rio de Janeiro: Nova Fronteira, 1985.

BARNES, John. Redes sociais e processo político. In: FELDMAN-BIANCO, B. (Org.). Antropologia das sociedades contemporâneas: métodos. São Paulo: Global, 1987.

BOTT, E. Familias e rede social. Rio de Janeiro: Francisco Alves, 1976.

BOURDIEU, P. La société traditionnelle: attitude à l'égard du temp et conduit économique. Sociologie du Travail, v. 1, n. 5, p. 24-44.1963.

. Le capital social: notes provisoires. Actes de la recherche en Sciences sociales, 1980.

BRESCIANI, S.; NAXARA, N. (Org.). Memória e (res)sentimento: indagações sobre um questão sensível.Campinas: Unicamp, 2004.

CALVINO, I. O Visconde Partido ao Meio. Rio de Janeiro: Nova Fronteira, 1925.

CASTEL, R. As metamorfoses da questão social. Uma crônica do salário. Petrópolis: Vozes, 2001. 
CAVALIERE, I.A.L. Hanseniano. Ser ou não ser interno: eis a questão. Cadernos Saúde Coletiva, Rio de Janeiro, v. XVII, n.1, p. 203-219 jan. mar. 2009.

CAVALIERE, I.A.L.; NASCIMENTO, D. Depoimentos orais sobre a repercussão da mudança do termo "lepra” para hanseníase. Oralidades: Revista de História Oral, n. 4, p. 111-127, jun-dez 2008.

CAVEDON, N. et al. Consumo, colecionismo e identidades dos bibliófilos: uma etnologia em dois sebos de Porto Alegre. Horizontes Antropológicos, ano 13, n. 28, p. 345-371, jul-dez, 2007.

CERTEAU, M. A invenção do cotidiano: arte de fazer. Petrópolis: Vozes, 1994.

CHALHOUB, S. Cidade febril: cortiços e epidemias na corte imperial. São Paulo: Cia das Letras, 1996.

CLARO, L. Hanseníase: representações sobre a doença. Rio de Janeiro: Fiocruz, 1995.

COIMBRA, M.C.C.; MANCUSO, M.I.R.; CARDOSO, M. Estigma e memória: uma apresentação. Estigma e memória: teoria e pesquisa, n. 16-17, p. 1-9, jan-jun 1996.

COSTA, S. Centralidade e magnitude da política de assistência social. Serviço e Sociedade, v. 99, p. 563-589, jul. set. 2009.

- Sociabilidades políticas e relações de gênero: ritos domésticos e religiosos no Rio de Janeiro do séc XIX. Revista Brasileira de História. São Paulo, v. 27, n. 54, p. 39-57, 2007. . Proteção social, maternidade transferida e lutas pela saúde reprodutiva. Rev. Estud. Fem., v. 10, n. 2, p. 301-323, 2002.

. Signos em transformação. A dialética de uma cultura profissional. São Paulo: Cortez, 1995.

DAMATTA, R. A casa e a rua. Rio de Janeiro: Guanabara, 1987.

DOIN, J. et al. A belle Époque caipira: problematização e oportunidades interpretativas da modernidade e urbanização no mundo do café (1852-1930) - a proposta do Cemusuc. Revista Brasileira de História. São Paulo, v. 27, n. 53, p. 91-122, 2007.

ECO, U. História da feiúra. Rio de Janeiro: Record, 2007.

ELIAS, N. Os estabelecidos e os outsiders: sociologia das relações de poder a partir de uma pequena comunidade. Rio de Janeiro: Jorge Zahar, 2000.

. A sociedade dos indivíduos. Rio de Janeiro: Jorge Zahar, 1994.

FONSECA, C. Família, fofoca e honra: etnografia de relações de gênero e violência em grupos populares. Porto Alegre: EdUFRGS, 2004.

FRANÇOIS, E. A fecundidade da história oral. In: AMADO, J.; FERREIRA, M.M. Usos e abusos da história oral. Rio de Janeiro: EdFGV, 1996.

FREIRE, M. Discurso maternalista em Revistas femininas (RJ e SP, década de 20). Tese (Doutorado em História das Ciências e da Saúde) - Casa de Oswaldo Cruz, Fundação Oswaldo Cruz, Rio de Janeiro, 2006. 
GINZBURG, C. Mitos, emblemas, sinais. São Paulo: Cia das Letras, 1991.

GOFFMAN, E. Manicômios, prisões e conventos. São Paulo: Perspectiva, 1974.

IGNATIEFF, M. Instituiçôes totais e classes trabalhadoras: um balanço crítico. Rev. Bras. de Hist., São Paulo, v. 7 n. 14, p. 185-193, mar-ago. 1987.

JOUTARD, P. Desafios à história oral do século XXI. In: FERREIRA, M.; FERNANDES, T.; ALBERTI, V (Org.). História oral: desafios para o século XXI. Rio de Janeiro: Fiocruz, 2000.

KOSELLECK, R. Futuro passado: contribuição à semântica dos tempos históricos. Rio de Janeiro. Contraponto, 2006.

LÉVI-STRAUSS, C. As estruturas elementares do parentesco. Petrópolis: Vozes, 1982.

LIMA, R. O município de Itaboraí recebe os "anjos inocentes": Hanseníase/Lepra - preconceitos e outras histórias. Trabalho de conclusão de curso. Departamento de História, Universidade Federal Fluminense, Niterói, 2005.

LOZANO, J. Prática e estilos de pesquisa na história oral contemporânea. In: AMADO, J.; FERREIRA, M.M. Usos e abusos da história oral. Rio de Janeiro: EdFGV, 1996. p. 15-25.

MACIEL, L. A solução do mal que é um flagelo: notas históricas sobre a hanseníase no Brasil do século XX. In: NASCIMENTO, D.R.; CARVALHO, D.M. (Org.). Uma história brasileira das doenças. Brasília: Paralelo 15, 2004, p. 109-125.

MANCUSO, M.I. O estigma da lepra: a experiência da exclusão. In: Estigma e memória: teoria e pesquisa, n. 16-17, p. 34-44, jan-jun 1996.

MAUSS, M. Ensaio sobre a dádiva. Forma e Razão da troca nas sociedades arcaicas. In: Sociologia e Antropologia, VII, São Paulo: EDUSP, 1974.

MORIGI, J.; PAVAN, C. Tecnologias de Informação e comunicação: novas sociabilidades nas bibliotecas universitárias. Cienc Inf. Brasília, v. 33, n. 1, p. 117-125, jan-abril 2004.

OBREGON, D. Batallas contra la lepra: Estado, Medicina y Ciência em Colômbia. Medellín: Fondo Editorial Universidad EAFIT, 2002.

PINTO, C. Redes sociais informais e integralidade nas políticas públicas. Trabalho de conclusão de curso. Departamento de História, Universidade Federal Fluminense, Niterói, 2007.

Família e rede social. Elizabeth Bott. Texto de fichamento para uso na disciplina: Sociologia da Família e do Cuidado. Estágio Docência no curso de graduação em Ciências Sociais UFF. Programa de Pós-Graduação em Antropologia, Universidade Federal Fluminense, Niterói, 2010.

PORTELLI, A. O massacre de Civitella Val di Chiana (Toscana, 29 de junho de 1944): mito e política, luto e senso comum. In: AMADO, J.; FERREIRA, M.M. Usos e abusos da história oral. Rio de Janeiro: EdFGV, 1996. p. 103-130.

PORTUGAL, S. Contribuições para uma discussão do conceito de rede na teoria 
sociológica. Oficina do CES, no 271, 2007. Disponível em: www.ces.uc.pt/publicacoes/ oficina/271/271.pdf Acessado em: 14 dez 2010.

ROUSSO, H. A memória não é mais o que era. In: AMADO, J.; FERREIRA, M.M. Usos e abusos da história oral. Rio de Janeiro: EdFGV, 1996. p. 93-101.

SARACENO, B. Libertando identidades. Da reabilitação psicossocial à cidadania possível. Belo Horizonte: Instituto Franco Basaglia, 1999.

SCOTT, J. Formas cotidianas da resistência camponesa. Revista Raizes, v. 21, n. 1, p. 10-31, 2002.

SIMMEL, G. Sociologia. São Paulo: Ática, 1983.

TEIXEIRA, F. L'Italia dei Divieti: entre o sonho de ser européia e o babado da prostituição. Cadernos Pagu, n. 31, p. 275-308, jul-dez 2008.

THOMPSON, E. Costumes em comum. São Paulo: Cia das Letras, 1998.

TRUZZI, O. Sociabilidades e valores: um olhar sobre a Família Árabe Muçulmana em São Paulo. DADOS. Revista de Ciências Sociais, Rio de Janeiro, v. 51, n. 1, p. 37-74, 2008.

WACQUANT, L. As duas faces do gueto. São Paulo: Boitempo, 2008.

WEBER, M. Capitalismo e sociedade rural na Alemanha. In: . Ensaios de Sociologia. 5.ed. Rio de Janeiro: Jorge Zahar Editor, 1979. p. 413-437.

ZELIZER, V. The purchase of intimacy. New Jersey: Princenton University Press, 2005.

\section{Notas}

${ }^{1}$ Em 1874, seu agente infeccioso, o bacilo Mycobacterium leprae, foi descoberto pelo médico e botânico norueguês Gerhard Armauer Hansen (MACIEL, 2004). Hansen, em outubro de 1897, na 1a Conferência Internacional de Leprologia, em Berlim, propôs o isolamento como modelo de profilaxia da doença devido à ausência de tratamento específico (OBREGÓN, 2002). O Brasil substituiu o termo "lepra", considerado pejorativo, por hanseníase, em homenagem a Hansen. Pretendeu, com isso, diminuir o estigma historicamente associado ao nome da doença (CAVALIERE; NASCIMENTO, 2008). Neste trabalho ambos serão utilizados.

${ }^{2}$ Foram entrevistados: Tereza, 71 anos, viúva, analfabeta, ingresso na CTM em 1963; Mariela, 57, casada, curso primário, ingresso na CTM em 1983; Jonas, 74 anos, casado, alfabetizado, ingresso na CTM em 1978; Eugenia, 94 anos, viúva, primário incompleto, ingresso na CTM em 1955; Soninha, 70 anos, viúva, primário incompleto, ingresso na CTM em 1949; Gorete, 40, solteira, primário incompleto, ingresso na CTM em 1985; Firmina, 43 anos, viúva, primário completo, ingresso na CTM em 1984.

${ }^{3}$ Para entrevistas, todas realizadas por Ivonete A. L. Cavaliere, foi obtido o termo de consentimento das pessoas entrevistadas, conforme Resolução no 196/96 do Conselho Nacional de Saúde, preservando-se seu anonimato com o uso de nomes fictícios.

${ }^{4} \mathrm{O}$ termo "interno", em pesquisa realizada na ex-Colônia Tavares de Macedo, segundo depoimentos orais de internos e funcionários, teria sido construído historicamente, situando modificações em múltiplas concepções vinculadas a experiências pessoais (CAVALIERE, 2009). 
${ }^{5}$ Há uma memória "oficial” que entende o massacre de Civitella como um episódio da resistência italiana local, definindo suas vítimas com mártires da liberdade, ao lado de memórias de sobreviventes, viúvas e filhos de outros significados (PORTELLI, 1996).

${ }^{6}$ Agradecemos a generosa contribuição de Camila Pinto Fernandes na indicação de textos de nosso interesse comum e de sua pesquisa como mestranda de Antropologia da UFF, em Niterói-RJ, 2010.

${ }^{7}$ Bourdieu conceitua capital social como "o conjunto de recursos, efetivos ou potenciais, relacionados com a posse de uma 'rede durável de relações', mais ou menos institucionalizadas, de interconhecimento e de reconhecimento" (BOURDIEU, 1980, p. 2).

${ }^{8}$ Sua ideia de rede social permitiu compreender como a família se articula com outros grupos e instituiçôes por meio de rede de relações pessoais que unem seus membros, ao dialogar com a sociologia da família: "O meio social imediato das famílias urbanas é mais bem compreendido, não como a área local em que vive a família, mas sim, como a rede das relações sociais reais que elas mantêm [...]” (BOTT, 1976, p. 111).

${ }^{9}$ Nesta perspectiva, rede difere de grupo, pois a noção de grupo implica totalidade e a rede se constrói, não da totalidade, mas a partir dos agentes, de unidades. A autora destaca que as pessoas se relacionam em contextos e intensidades diferentes, mesmo que estes relacionamentos sejam com as mesmas pessoas a partir de questôes similares. 


\section{Abstract}

\section{Social isolation, sociability and social care networks}

This exploratory work examines the social isolation experienced by individuals with leprosy admitted to the former colony Tavares de Macedo, Itaboraí, where they were kept from the 1930s until the present day, to question notions of segregation and social discrimination present in this environment. So it analyzes sociabilities and social care networks established in the common life in this "ex-leper colony," usually as alternatives to the conditions offered by the public systems of social protection. The work is based on stories of some of the subjects, seen in their differences - at intersection of gender relations, classes, races/ ethnicities, generations and also by religions and educational backgrouns. It adopts the oral history, so as to offer new qualitative interpretations of social and historical processes shown in these networks and sociability, not always visible as unique forms of social protection of life in groups.

> Key words: social protection; social subjects; social isolation. 